\title{
Instrumentation of a robotic arm with graphical interface
}

\author{
Jonny Carmona Reyes*, Moisés Sánchez Moredia**, Bryan Zúñiga Barrientos ${ }^{* * *}$, Ytan Oscar Paredes Armenta ${ }^{* * * *}$, \\ David Briones García******
}

Technological University of Tlaxcala

DOI: 10.29322/IJSRP.10.11.2020.p10754

http://dx.doi.org/10.29322/IJSRP.10.11.2020.p10754

\begin{abstract}
The present project consists in the effective instrumentation of a robotic arm to control it, improving the precision of its movements and monitoring its position, to later control the movements of the arm. A graphical interface was created in the Processing platform that shows the position of each arm joint and at the same time it helps to manipulate its movements. The computer induces the Processing program to send instructions to the Arduino board based on the value of the virtual knob that the operator entered.
\end{abstract}

Index Terms- Arduino, Graphical interface, Instrument, Processing, Robotic arm, Raspberry

\section{INTRODUCTION}

$\mathrm{T}$ he use of instruments dates back to the beginning of human civilization. As man developed, there was also a growing need to measure certain parameters that were required to reduce his daily activities, such as weight, temperature, time or flow. Industrially, in the early 1920 s, the formal development of instrumentation took place due to the requirements of new industrial processes, such as oil refining, dairy pasteurization or electricity generation. Instrumentation has allowed current technological advancement such as the automation of industrial processes, since automation is only possible through elements that can measure physical variables and/or transmit what happens in the environment, in order to take an action of pre-programmed control that acts on the system to alter said variable obtaining the expected result. Instrumentation is the set of sciences and technologies by which physical or chemical variables are measured for evaluations and/or actions based on the information obtained.

With the characteristics it possesses, instrumentation implementations can be carried out in different areas, processes, equipment and tools, such as a robotic arm, one of the most widely used tools in today's industry. This device is one of the present technological culminations that have been developing since the end of the 18th century and the beginning of the 19th century, when numerical control programmed machines for industrial use began to be implemented, such as a weaving machine for the textile industry in which it was possible to choose the type of loom to weave using punched cards. This machine was part of the beginning of automation.

Thus, it is possible that through instrumentation, a robotic arm can be enabled, measuring analog and location variables, to interpret, evaluate and subsequently alter them, resulting in easy manipulation of the arm and optional automation of the same for processes and tasks that it's capable of carrying out, and therefore could be useful, for example, for assembly on a production line, or as a learning prototype to configure a series of instructions to be performed as practice. 


\section{THEORETICAL FRAMEWORK}

Raspberry

"The Raspberry $\mathrm{Pi}$ is a low-cost reduced board computer, single board computer or simple board computer (SBC) developed in the UK by the Raspberry Pi Foundation." (Sánchez, 2018, p. 21).

The Raspberry board can perform the same tasks as a normal computer, such as play audio, play video, play games, surf the Internet or manipulate documents.

Processing

Processing is an open source software, and anyone can contribute to its improvement. Without unnecessary interfaces, it uses a Javabased programming language (of the same name). It basically consists of a simple text editor to write code, a message area, a text console, a tab system to manage files, a toolbar with common action buttons and a menu bar (Buioli and Pérez, 2013 , p. 4).

\section{Arduino}

Arduino is a single-board free hardware microcontroller system, easy to use and of low cost, initially developed to facilitate the use of electronics in artistic and interactive designs and its application by non-experts. To facilitate its use and programming, an IDE (integrated development environment) was developed simultaneously and together with the Arduino platform, in which a programming language similar to $\mathrm{C}++$ is used, based on the Wiring language, the development environment is based on Processing (Herrero and Sánchez, 2015, p. 4).

\section{METHODOLOGY AND DEVELOPMENT}

The following diagram represents the system created to control the robotic arm:

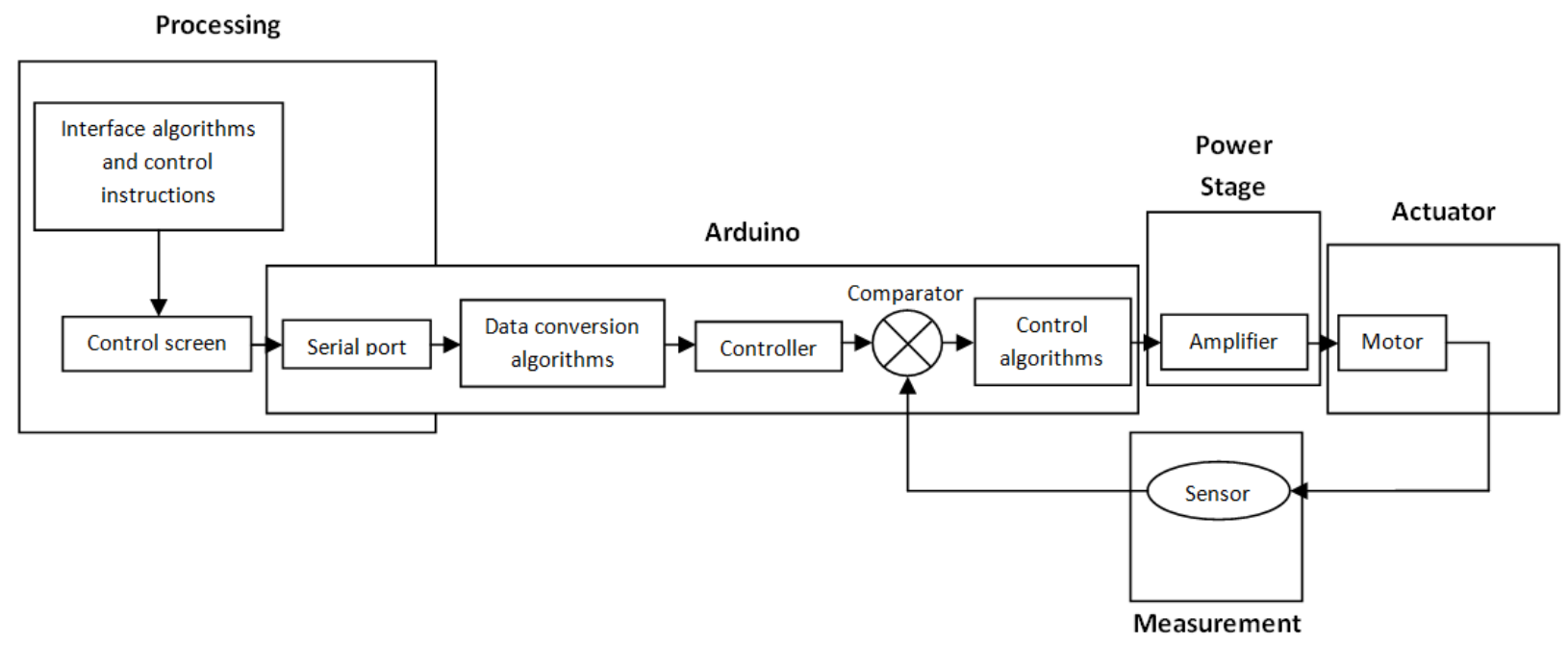

Figure 1: System diagram. Source: own elaboration. 2020.

- Interface algorithms and control instructions: These are the algorithms that will provide the design and image to the interface, such as the algorithm called "event" which detects each value sent to the serial monitor through a specific point on the screen.

- Control screen: Provides the main view of the control interface where it has display and control algorithms, as shown in figure 2 . 


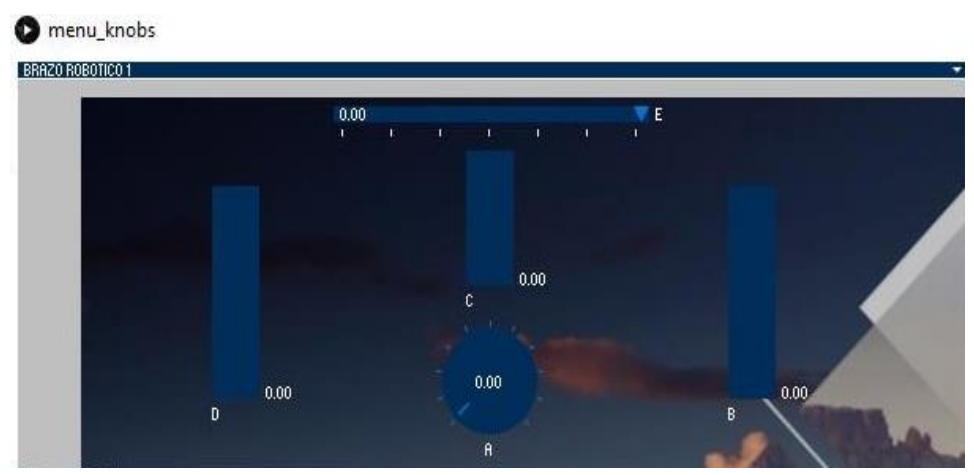

Figure 2: Control interface. Source: own elaboration. 2020.

- Serial Port: A COM port is a serial port on a computer, which is a slot that allows the connection of peripheral devices (such as a mouse or modem) to the computer via cable. They have been replaced by the small USB (Universal Serial Bus) connectors and in this case, a virtual serial port was used to communicate Processing and Arduino.

- Data conversion algorithms: In the main program the data sent from Processing is read and Arduino stores this data in programmed places according to the type of value that arrives, in this case characters of the type "char" are handled.

- Controller: The controller is characterized by having the code that will be able to perform the tasks assigned to it with the help of its analog type connection pins for reading and controlling digital signals.

- Comparator: Its task is to compare the sensor position readings and measure how far the robotic arm is from the position that is requested and for this, the program makes the decision to send a pulse to two pins destined as left or right to control the rotation of a motor in either of these directions.

- Amplifier: Since the Arduino signal goes from 0 to 5 volts and our motors need 7 volts, the voltage is insufficient, so a power stage with a 1293D Driver is used, which is an integrated circuit designed to control motors using an $\mathrm{H}$ bridge . It has 4 channels, and it's capable of being designed to handle 2 channels and full $\mathrm{H}$ bridge. This way it was possible to design the circuit board for the power stage as shown in figure 3 .

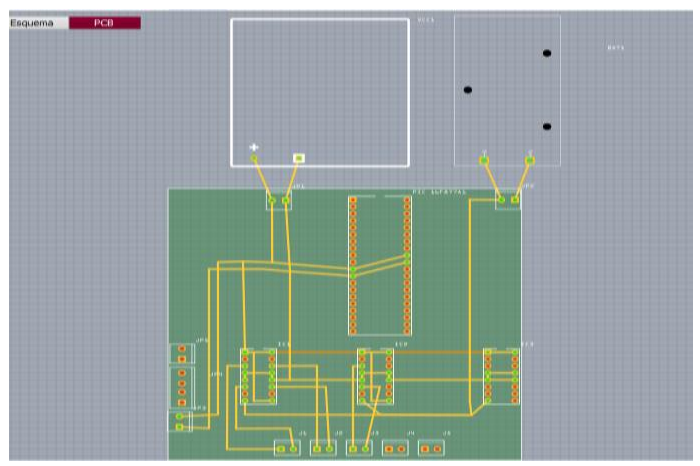

Figure 3: Power stage circuit board. Source: own elaboration. 2020.

- Motor: In this section the actuators are manipulated by the entire closed loop type control system.

- Sensor: It's a potentiometer coupled to the motor to obtain its position. This data is monitored by the microcontroller to define what decision will be made according to what the user wants. 


\section{Development}

The first step was to experiment with potentiometers attached to the joints of the robotic arm (see figure 4) to obtain measurements of the movement variables in order to manipulate them. For this, and with the help of Arduino, tests were carried out by sending numerical data to observe the adjustment of the movements of each joint; the potentiometers then sent analog values from 0 to 1024 . With the help of the "map" function a conversion of these values to degrees was made, obtaining measurements of the position of each joint, adjusting to the required location using the $5 \mathrm{~V}$ motors. In this last part, a power drop was discovered in the motors when energized, for this reason, a power amplification stage was added to compensate for it.

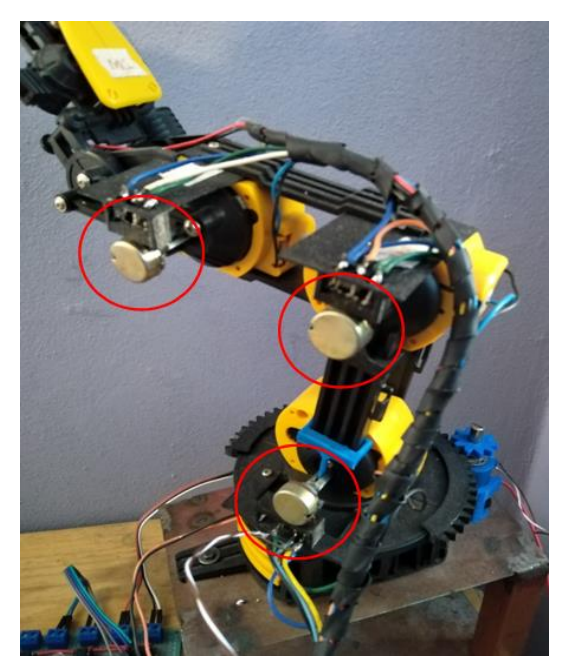

Figure 4: Robotic arm with potentiometers attached to it. Source: own elaboration. 2020.

Once the method to manipulate the location values of the arm was known, a graphical user interface (GUI) was created with the help of the Processing software, for this, we started by creating virtual knobs and sliders using the "ControlIP5" library. The values sent by Processing are marks and numeric values, which Arduino stores for a short period of time and defines the destination of the signal, that is, to which joint it sends it to move it.

Once the Arduino board is ready to send the signal, it first passes through the power amplifier to provide enough power to compensate for the aforementioned power drop and move the target motor, as well as making it possible to reverse its rotation.

To make the transport of this entire system more practical, it was adapted to a touch screen and Raspberry pc board, the GUI appears on the screen, showing the virtual knobs with their sliders to facilitate manipulation for the operator.

\section{RESULTS}

According to the movement instructions that the user enters to control each joint, the arm takes approximately two seconds to perform the movement; however, the movement is precise. Thus, a practical and intuitive system that anyone can use is obtained.

\section{CONCLUSIONS}

The design and its components, although practical, can still be improved in different ways, such as using flex sensors instead of potentiometers, reducing the response time of the arm when an instruction is entered in the interface, and so on. As it is a system created in free software, new conditions or algorithms can be introduced to adjust the program to different needs. 


\section{REFERENCES}

[1] José Carlos Herrero Herranz, Jesús Sánchez Allende. (2015). UNA MIRADA AL MUNDO ARDUINO. Madrid: Separata.

[2] Juan V. Capella. (2015). Programando en Java Raspberry Pi (RPi). Valencia: Universidad Politécnica de Valencia.

[3] Casey Reas, Ben Fry. (2007). Processing: A Programming Handbook for Visual Designers and Artists. London, England: MIT Press.

[4] Ignacio Buioli, Jaime Pérez Marín. (2013). Processing: Un lenguaje al alcance de todos. Londres: MIT Press.

\section{AUTHORS}

First Author - Jonny Carmona Reyes, graduated in 2010 from the Electronic Engineering career at the Technological Institute of Apizaco with the specialty of Automation and Instrumentation. jonny.carmona.ita@.gmail.com

Second Author - Moisés Sánchez Moredia, obtained a Bachelor's degree in Applied Modern Languages, with a specialization in teaching English as a second language from the Autonomous University of Tlaxcala. Tr. Sánchez also has a Master's Degree in School Administration and Management from the International University of La Rioja (UNIR). mysuitablenglish@gmail.com

Third Author - Bryan Zúñiga Barrientos, graduated in 2019 as superior technician in Industrial Maintenance at the Technological University of Tlaxcala. bryantzuniga73@gmail.com

Fourth Author - Ytan Oscar Paredes Armenta, graduated in 2019 as superior technician in Industrial Maintenance at the Technological University of Tlaxcala. paredes.ytan@gmail.com

Fifth Author - David Briones García, graduated in 2019 as superior technician in Industrial Maintenance at the Technological University of Tlaxcala. davidbga312@gmail.com

Correspondence Author - Ytan Oscar Paredes Armenta, paredes.ytan@gmail.com, +522411187353 